\title{
EFFECTIVE TREATMENT OF HOSPITAL WASTEWATER WITH HIGH-CONCENTRATION DICLOFENAC AND IBUPROFEN USING A PROMISING TECHNOLOGY BASED ON DEGRADATION REACTION CATALYZED BY FEO UNDER MICROWAVE IRRADIATION
}

\author{
Yasmin Vieira; Hércules A. Pereira; Jandira Leichtweis; Clóvia M. \\ Mistura; Edson L. Foletto; Luis F.S. Oliveira; Guilherme L. Dotto
}

\begin{abstract}
Real hospital wastewater was effectively treated by a promising technology based on degradation reaction catalyzed by $\mathrm{Fe} 0$ under microwave irradiation in this work. $\mathrm{Fe} 0$ powders were synthesized and characterized by different techniques, resulting in a single-phase sample with spherical particles. Optimum experimental conditions were determined by a central composite rotatable design combined with a response surface methodology, resulting in $96.8 \%$ of chemical oxygen demand reduction and $100 \%$ organic carbon removal, after applying MW power of $780 \mathrm{~W}$ and $\mathrm{Fe} 0$ dosage of $0.36 \mathrm{~g} \mathrm{~L}-1$ for $60 \mathrm{~min}$. Amongst the several organic compounds identified in the wastewater sample, diclofenac and ibuprofen were present in higher concentrations; therefore, they were set as target pollutants. Both compounds were completely degraded in $35 \mathrm{~min}$ of reaction time. Their plausible degradation pathways were investigated and proposed. Overall, the method developed in this work effectively removed high concentrations of pharmaceuticals in hospital wastewater.
\end{abstract}

\section{Keywords}

Hospital wastewater; Ibuprofen; Diclofenac; Degradation; Microwave; Zero-valent iron 